\title{
Detection of tamarixetin and kaempferide in different tissues by high-performance liquid chromatography in tamarixetin and kaempferide treated rats
}

\author{
Fu-quan $\mathrm{Xu}^{1 *}$, Yuan-yuan Feng ${ }^{2}$ and Bin-Iun Yan ${ }^{1}$ \\ ${ }^{1}$ Jiangsu Key Laboratory of Marine Biotechnology, Huaihai Institute of Technology, Lianyungang 222005, \\ People's Republic of China. \\ ${ }^{2}$ Department of Electronic Engineering, Huaihai Institute of Technology, Lianyungang 222005, \\ People's Republic of China.
}

Received 18 August, 2011; Accepted 21 December, 2011

\begin{abstract}
Tamarixetin and kaempferide were considered as the major active constituents of Tamarix chinensis, and had several known bioactivities. An effective and inexpensive high-performance liquid chromatographic method was established and validated for the determination of tamarixetin and kaempferide in rat tissues following a single oral administration. Tissue distribution showed the highest level of tamarixetin was observed in lung, then in heart; and the highest concentration of kaempferide was determined in heart.
\end{abstract}

Key words: Liquid chromatography, tissues distribution, tamarixetin, kaempferide.

\section{INTRODUCTION}

The twig of Tamarix chinensis was used for the treatment of coughs with dyspnea and wind chill cold in Chinese folk (National Pharmacopoeia Commission, 2005). Tamarixetin and kaempferide were considered as the major active constituents of $T$. chinensis (Zhang et al., 1991). Tamarixetin had been found to have antibacterial (Sultanova et al., 2001), free radical scavenging (Fazilatun et al., 2005; Nessa et al., 2004), hepatic protective (Yannai et al., 1998) and antioxidant activity (von Moltke et al., 2004). Kaempferide was reported had the peroxynitrite free radical scavenging (Calgarotto et al., 2007), antitrypanosomal and antileishmanial (Tasdemir et al., 2006), antioxidant activities (Burda and Oleszek, 2001). Among variety of bioactive flavonoids, which were in took by daily dietary (Androutsopoulos et al., 2010), tamarixetin and kaempferide were widely found in many plants (Lai et al., 2007). With the growing significance of a potential beneficial role of tamarixetin and kaempferide in human health, there is a demand for analyzing them simultaneously. thin-layer chromatography (TLC), highperformance liquid chromatography (HPLC) and liquid chromatography-mass spectrometry (LC-MS) had been applied to quantification of tamarixetin or kaempferide from various herbal medicines and foods (Liang et al., 2009; Lai et al., 2007; Wang et al., 2008; Paulke et al., 2006), but no simultaneous determination reported in crude plant's extract and biological fluids, let alone in tissues. It is well known that tissue distribution can help predict a variety of events related to the efficacy and toxicity of herbal preparations. Therefore, it is necessary for an intensive investigation on tissue distribution of tamarixetin and kaempferide for a good understanding of the mechanism of action and facilitating further research and development of $T$. chinensis. In the present paper, 
we developed and validated a rapid and sensitive HPLC method to determine tamarixetin and kaempferide in rat tissues. The method was successfully applied to tissue distribution study after oral administration of $600 \mathrm{mg} / \mathrm{kg}$ the total flavonoides from $T$. chinensis to healthy rats.

\section{MATERIALS AND METHODS}

\section{Chemical, reagents and animals}

Tamarixetin and kaempferide were isolated from thin-film transistor (TFT) their structures were identified on the basis of spectral data (Galeotti et al., 2008; Blasa et al., 2011) and the purity was $>98.5 \%$. Quercetin used as internal standard (IS) and its purity was $>99.0 \%$. HPLC-grade methanol was purchased from Honeywell International (Burdick and Jackson, Muskegon, MI, USA). Analytical and $\mathrm{C}_{18}$ cartridge columns were purchased from Waters (Waters, Milford, MA, USA). Pure tamarixetin and kaempferide solutions were prepared in methanol to furnish working solutions at concentrations $800,400,160,80,16,8,3.2,1.6 \mu \mathrm{g} \mathrm{mL}^{-1}$ and $1400,700,280,140$, $28,14,5.6,2.8 \mathrm{\mu g} \mathrm{mL}^{-1}$, respectively. Their working solutions were added to different tissue homogenates of untreated rat and obtained the standard calibration sample in the concentration range of 0.32 to $160 \mathrm{\mu g} \mathrm{mL}^{-1}$ and 0.28 to $280 \mathrm{\mu g} \mathrm{mL}^{-1}$. Quercetin solution of concentration $275 \mu \mathrm{g} \mathrm{mL}^{-1}$ was prepared in methanol. All the solutions were stored at $-20^{\circ} \mathrm{C}$ and were brought to room temperature before use. Wistar rats (male, 170 to $190 \mathrm{~g}$ ) were purchased from Qingdao Institute of Drug Control (Qingdao, P. R. China), and kept in environmentally controlled breeding room (relative huminidity: $65 \%$, temperature: $23 \pm 2^{\circ} \mathrm{C}, 12 \mathrm{~h}$ light-12 $\mathrm{h}$ dark cycle) for three days before the test, fed with food and water ad arbitrium. All animal studies were performed according to the requirement of the National Act on the Use of Experimental Animal (China).

\section{Instrumentation}

LC analysis was performed on Waters 2695 high performance liquid chromatography system equipped with diode array detector (2996) and Empower software (Waters, Milford, MA, USA). A Waters Sunfire ${ }^{\mathrm{TM}} \mathrm{C}_{18}$ reversed-phase column (5 $\mu \mathrm{m}$ particles, $250 \mathrm{~mm} \times 4.6$ $\mathrm{mm}$ ) was used for separation and quantification.

\section{Chromatographic conditions}

The mobile phase for tissue samples was a gradient prepared from methanol (component $\mathrm{A}$ ) and $0.15 \%$ aqueous formic acid solution

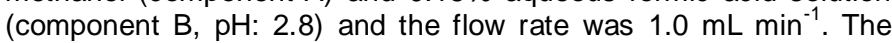
initial mobile phase composition condition was $A$ to $B$ 10:90 (v/v). This was changed linearly to $A$ to $B 35: 65(\mathrm{v} / \mathrm{v})$ at $15 \mathrm{~min}$ and held at this composition until $25 \mathrm{~min}$, the composition was changed linearly to $A$ to $B \quad 60: 40(\mathrm{v} / \mathrm{v})$ at $40 \mathrm{~min}$. Chromatograms were monitored at $254 \mathrm{~nm}$ and the temperature of column was kept at $35^{\circ} \mathrm{C}$.

\section{Sample preparation}

$0.2 \mathrm{~g}$ tissues (heart, liver, spleen, lung, kidney, prostate and brain) were shredded in ice-bath, and then homogenized in $2 \mathrm{~mL}$ ice-cold $1 \%$ phosphoric acid normal saline solution. The homogenate was added $10 \mu \mathrm{L}$ IS and vortex-mixed for $60 \mathrm{~s}$. The supernatant, prepared by centrifugation at $6000 \mathrm{rpm}(10 \mathrm{~min})$, was extracted by $\mathrm{C}_{18}$ cartridge and eluted with water $(0.6 \mathrm{~mL})$ and methanol $(0.6 \mathrm{~mL})$ successively. The methanol fraction was evaporated to dryness under a stream of nitrogen at $40^{\circ} \mathrm{C}$. The residue was redissolved in $150 \mu \mathrm{L}$ of methanol, and then stored $30 \mathrm{~min}$ at $4^{\circ} \mathrm{C}$. A $10 \mu \mathrm{L}$ aliquot was injected into the high performance liquid chromatography system after centrifugation at $12000 \mathrm{rpm}$ for $10 \mathrm{~min}$.

\section{Method validation}

Calibration curves were constructed by plotting peak area versus concentrations in the standard samples. The limit of detection (LOD) and limit of quantitation (LOQ) were determined to evaluate the sensitivity, defined as the concentration that produced a signalto-noise ratio of $3: 1$ and 10:1, respectively. Intra- and inter-day precision, assessed by relative standard deviation (RSD) and mean concentration, were measured by performing replicate analysis $(n=$ 5) for each concentration within one day and three continual days. The recoveries from tissue samples were calculated by comparing peak areas extracted from tissue samples with those of the same quantities added to the mobile phase. The freeze-thaw stability was tested after frozen at $-20^{\circ} \mathrm{C}$ for $24 \mathrm{~h}$ and completely thawed at room temperature. The long-time stability and short-time stability was assessed within 30 days and $24 \mathrm{~h}$ storage periods. All samples were tested at three concentration levels and repeated at least three times in method validation section.

\section{Tissues distribution study}

Tissues of 25 rats were removed at 10, 30, 60, 90 and 120 min after dosing $600 \mathrm{mg} \mathrm{kg}^{-1} \mathrm{TFT}$, washed with physiological saline solution and blotted dry twice, finally weighed and stored at $-20^{\circ} \mathrm{C}$ until disposal (within $24 \mathrm{~h}$ ). Blank tissues were collected from rats free of TFT and processed as tissue samples.

\section{RESULTS AND DISCUSSION}

\section{Extraction recovery}

In different tissues, the range of two analytes was from 86.6 to $99.2 \%$ and from 87.1 to $101 \%$ and not less than $89.7 \%$ for IS. The results guaranteed the established method was suitable for tissue distribution study of tamarixetin and kaempferide.

\section{Selectivity}

The interference in tissue homogenate made it difficult to determine analytes exactly, after treaded in this study, the endogenous components were not appeared at the retention time of analytes in tissue analysis (Figure 1). It was concluded that acceptable selectivity was obtained by using the developed method.

\section{Precision and accuracy}

The measured mean concentration was very close to the added concentration ( $>91.3 \%)$ and the RSD of tamarixetin and kaempferide was less than $5.03 \%$ and $4.12 \%$, respectively, which indicated that the developed method had good precision and accuracy for tissue 

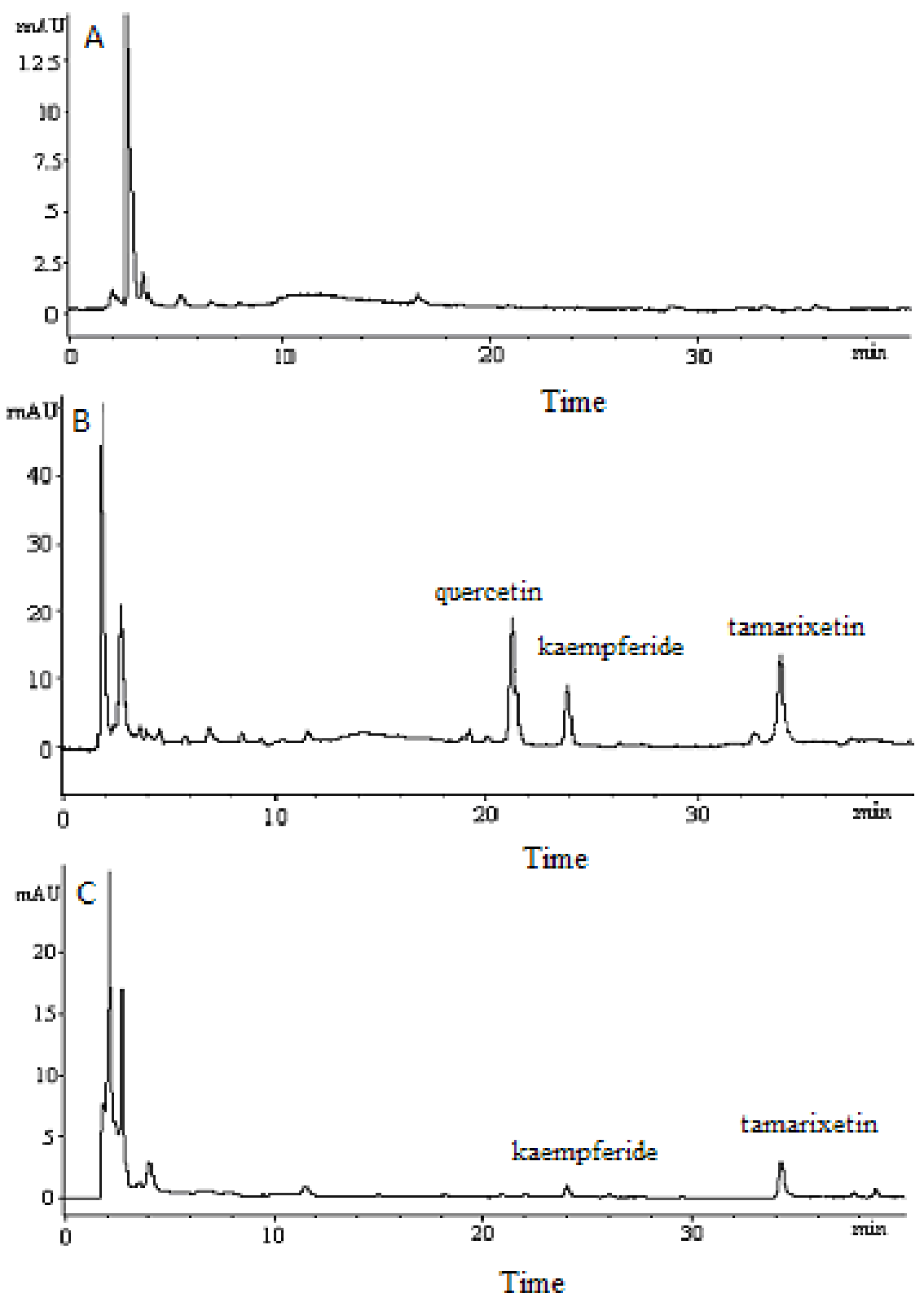

Figure 1. Chromatographic profiles of tissue samples: blank heart; $\mathbf{A}$, blank heart spiked with tamarixetin, kaempferide and quercetin; B, heart obtained at $30 \mathrm{~min}$; C.

\section{Calibration curves and sensitivity}

Calibration curves were shown as follows: heart (kaempferide: $Y=0.00336 X+0.0411, r=0.994,0.28$ $280 \mu \mathrm{g} \mathrm{mL} \mathrm{L}^{-1}$, tamarixetin: $Y=0.00352 X+0.0341, r=$ $0.993,0.32-160 \mu \mathrm{g} \mathrm{mL} \mathrm{m}^{-1}$ ), liver (kaempferide: $Y=$ $0.00343 X+0.0423, r=0.996,0.28-280 \mu \mathrm{g} \mathrm{mL} \mathrm{m}^{-1}$, tamarixetin: $Y=0.00347 X+0.0402, r=0.996,0.32-160$ $\mu \mathrm{g} \mathrm{mL}^{-1}$ ), spleen (kaempferide: $Y=0.00341 X+0.0435, r$ $=0.995,0.28-280 \mu \mathrm{g} \mathrm{mL}^{-1}$, tamarixetin: $Y=0.00354 X+$ $0.0369, r=0.996,0.32-160 \mu \mathrm{g} \mathrm{mL}^{-1}$ ), lung (kaempferide: $Y=0.00332 X+0.0431, r=0.993,0.28-280 \mu \mathrm{mL}^{-1}$, tamarixetin: $Y=0.00338 X+0.0472, r=0.991,0.32-160$ $\mu \mathrm{gL} \mathrm{m}^{-1}$ ), kidney (kaempferide: $Y=0.00329 X+0.0443, r$ $=0.994,0.28-280 \mathrm{~g} \mathrm{~mL}^{-1}$, tamarixetin: $Y=0.00342 X+$ $0.0360, \quad r=0.995,0.32-160 \mu \mathrm{g} \mathrm{mL} \mathrm{mL}^{-1}$ ), prostate (kaempferide: $Y=0.00334 X+0.0433, r=0.990,0.28$ $280 \mu \mathrm{g} \mathrm{mL}^{-1}$, tamarixetin: $Y=0.00346 X+0.0373, r=$ 0.994, 0.32-160 $\mathrm{gg} \mathrm{mL}^{-1}$ ), brain (kaempferide: $Y=$ $0.00343 X+0.0414, \quad r=0.995, \quad 0.28-280 \mu \mathrm{g} \mathrm{mL}^{-1}$, tamarixetin: $Y=0.00337 X+0.0318, r=0.993,0.32-160$ $\left.\mu \mathrm{g} \mathrm{m}^{-1}\right) . Y$ was peak area ratio and $X$ represented the concentration $\left(\mu \mathrm{g} \mathrm{mL}^{-1}\right)$ in the linear regression equation. The LOD and LOQ of this method were 0.06 and $0.16 \mu \mathrm{g}$ $\mathrm{mL}^{-1}$, which was the foundation of HPLC method for tissue distribution study. 
Table 1. The results of tamarixetin and kaempferide in tissues $\left(\mu \mathrm{gL}^{-1}\right)(\mathrm{n}=5)$.

\begin{tabular}{lccccccc}
\hline Compound & Liver & Heart & Spleen & Lung & Kidney & Prostate & Brain \\
\hline Tamarixetin (at 10 min) & 0.57 & 1.45 & 0.32 & 1.34 & 0.56 & 0.15 & 0.28 \\
Kaempferide (at 10 min) & 0.32 & 0.76 & 0.24 & 0.85 & 0.15 & 0.16 & 0.21 \\
Tamarixetin (at 30 min) & 1.76 & 2.14 & 0.37 & 2.31 & 1.21 & 0.31 & 0.45 \\
Kaempferide (at 30 min) & 0.84 & 1.08 & 0.26 & 1.07 & 0.28 & 0.22 & 0.14 \\
Tamarixetin (at 60 min) & 0.24 & 0.37 & 0.45 & 1.13 & 1.45 & 0.23 & 0.72 \\
Kaempferide (at 60 min) & 0.14 & 0.21 & 0.18 & 0.60 & 0.72 & 0.17 & 0.34 \\
\hline
\end{tabular}

\section{Stability}

The analytes stability was evaluated by long-time, shorttime and freeze-thaw stability experiment. The recoveries of freeze-thaw stability after three cycles were 88.7 to $92.1 \%$ (tamarixetin) and 86.3 to $93.5 \%$ (kaempferide). The values of short-time stability were no less than $86.4 \%$ (tamarixetin) and $87.3 \%$ (kaempferide), and the long-time stability results were more than $89.6 \%$ (tamarixetin) and $92.1 \%$ (kaempferide). These results indicated that all the biological samples were stable after three freeze $\left(-20^{\circ} \mathrm{C}\right)$ thaw cycles, for $24 \mathrm{~h}$ at room temperature and for 30 days at $-20^{\circ} \mathrm{C}$, with a reduction of less than $15 \%$.

\section{Tissues distribution}

Concentrations of tamarixetin and kaempferide were determined in various tissues of rat such as heart, liver, lung, spleen, kidney, prostate and brain, respectively. At 30 min after oral administration of TFT to rats, high level of two analytes was observed in heart, liver and lung, and at $60 \mathrm{~min}$ the high tissues were spleen, kidney and brain. Tamarixetin and kaempferide were few in all collected tissues after $90 \mathrm{~min}$ and were undetectable in most tissues after $120 \mathrm{~min}$; there was no long-term accumulation after administration. Table 1 showed the concentrations of the tamarixetin and kaempferide in rat tissues at 10, 30 and 60 min after oral dose of TFT. This study showed that analytes was mainly distributed in abundant blood-supply tissues such as lung, liver and heart, which implied that the distribution of analytes maybe depended on the blood flow. The high distribution in lung confirmed that the twig of $T$. chinensis could treat cough.

\section{Conclusion}

The assay procedure presented in this report provides a simple, rapid and sensitive procedure for the determination of tamarixetin and kaempferide in tissues after oral administration to rats. The achieved tissue distribution results may be useful for further study of TFT, and be good for the development of T. chinensis to modern medicine. This was the first study of tamarixetin and kaempferide on tissue distribution after oral administration of TFT to rats.

\section{ACKNOWLEDGMENTS}

The work received financial support from the Natural Science Foundation of Huaihai Institute of Technology (No. KQ09040, KX10051).

\section{Conflict of Interests}

The author(s) have not declared any conflict of interests.

\section{REFERENCES}

Androutsopoulos VP, Papakyriakou A, Vourloumis D, Tsatsakis AM, Spandidos DA (2010). Dietary flavonoids in cancer therapy and prevention: substrates and inhibitors of cytochrome P450 CYP1 enzymes. Pharmacol. Ther. 126:9-20.

Blasa M, Angelino D, Gennari L, Ninfali P (2011). The cellular antioxidant activity in red blood cells (CAA-RBC): A new approach to bioavailability and synergy of phytochemicals and botanical extracts. Food Chem. 125:685-691.

Burda S, Oleszek W (2001). Antioxidant and antiradical activity of flavonoids. J. Agric. Food. Chem. 49:2774-2779.

Calgarotto AK, Miotto S, Honorio KM, da Silva ABF, Marangoni S, Silva JL, Comar Jr. M, Oliveira KMT, da Silva SL (2007). A multivariate study on flavonoid compounds scavenging the peroxynitrite free radical. J. Mol. Struct. Theochem. 808:25-33

Fazilatun N, Nornisah M, Zhari I (2005). Superoxide radical scavenging properties of extracts and flavonoids isolated from the leaves of Blumea balsamifera. Pharm. Biol. 43:15-20.

Galeotti F, Barile E, Curir P, Dolci M, Lanzotti V (2008). Flavonoids from carnation (Dianthus caryophyllus) and their antifungal activity. Phytochem. Lett. 1:44-48.

Lai JP, Lim YH, Su J, Shen HM, Ong CN (2007). Identification and characterization of major flavonoids and caffeoylquinic acids in three Compositae plants by LC/DAD-APCI/MS. J. Chromatogr. B. 848:215225.

Liang X, Zhang X, Dai W, Lv Y, Yan S, Zhang W (2009). A combined HPLC-PDA and HPLC-MS method for quantitative and qualitative analysis of 10 major constituents in the traditional Chinese medicine Zuo Gui Wan. J. Pharm. Biomed. Anal. 49:931-936

National Pharmacopoeia Commission (2005). Chinese Pharmacopeia Chemical Industry Press, Beijing, p. 187.

Nessa F, Ismail Z, Mohamed N, Haris MRHM (2004). Free radicalscavenging activity of organic extracts and of pure flavonoids of Blumea balsamifera DC leaves. Food Chem. 88:243-252.

Paulke A, Schubert-Zsilavecz M, Wurglics M (2006). Determination of 
St. John's wort flavonoid-metabolites in rat brain through high performance liquid chromatography coupled with fluorescence detection. J. Chromatogr. B. Anal. Technol. Biomed. Life Sci. 17:832(1):109-113.

Sultanova N, Makhmoor T, Abilov ZA, Parween Z, Omurkamzinova VB, ur-Rahman A, Choudhary MI (2001). Antioxidant and antimicrobial activities of Tamarix ramosissima. J. Ethnopharmacol. 78:201-205.

Tasdemir D, Kaiser M, Brun R, Yardley V, Schmidt TJ, Tosun F, Rüedi P (2006). Antitrypanosomal and antileishmanial activities of flavonoids and their analogues: in vitro, in vivo, structure-activity relationship, and quantitative structure-activity relationship studies. Antimicrob. Agent Chemother. 50:1352-1364.

von Moltke LL, Weemhoff JL, Bedir E, Khan IA, Harmatz JS, Goldman P, Greenblatt DJ (2004). Inhibition of human cytochromes P450 by components of Ginkgo biloba. J. Pharm. Pharmacol. 56:1039-1044.
Wang X, Sun W, Sun H, Lv H, Wu Z, Wang P, Liu L, Cao H (2008). Analysis of the constituents in the rat plasma after oral administration of Yin Chen Hao Tang by UPLC/Q-TOF-MS/MS. J. Pharm. Biomed. Anal. 46:477-490.

Yannai S, Day AJ, Williamson G, Rhodes MJ (1998). Characterization of flavonoids as monofunctional or bifunctional inducers of quinone reductase in murine hepatoma cell lines. Food Chem. Toxicol. 36:623-630.

Zhang XY, Ling LQ, Wang HK (1991). Chemical composition of Cacumen Tamaricis . Zhong. Cao. Yao 22:299-300. 